\title{
PREVALENCE AND RISK FACTORS OF BLASTOCYSTIS SP. INFECTION AMONG PRIMARY SCHOOL CHILDREN IN A RURAL COMMUNITY, CENTRAL THAILAND
}

\author{
Witchakorn Trisukon*, Mathirut Mungthin**, Phunlerd Piyaraj**, Saovanee Leelayoova**, Tawee Naaglor**, \\ Ram Rangsin***, Duangnate Siripatpisitpong****, Ratchaneewan Aunpad****, Paanjit Taamasri**, \\ Picha Suwannahitatorn** \\ * $5^{\text {th }}$ year Medical Cadet, Phramongkutklao College of Medicine, Bangkok, Thailand \\ ** Department of Parasitology, Phramongkutklao College of Medicine, Bangkok, Thailand \\ *** Department of Military and Community Medicine, Phramongkutklao College of Medicine, Bangkok, Thailand \\ **** Department of Medical Technology and Graduate Program of Biochemical Sciences, Faculty of Allied Health \\ Science, Thammasart University, Bangkok, Thailand
}

\begin{abstract}
Background: Blastocystis sp., a protozoan parasite, has been globally reported as one of the most common intestinal parasitic infections among humans. Water transmission plays an important role for the route of transmission of this organism to humans.

Objectives: To determine the prevalence and risk factors of Blastocystis sp. infection among school children in a rural community, central Thailand.

Materials and Methods: In November 2015, school children from four primary schools (Schools A, B, C and D) in a rural community of Sanam Chai Kate District, Chacheongsao Province, central Thailand were enrolled in the study. Stool samples collected from participants were examined using wet preparation, phosphate buffered saline-ethyl acetate and Kato-Katz techniques. Short-term cultivation for Blastocystis sp. was performed using Jone's medium supplemented with $10 \%$ horse serum. Strongyloides stercoralis was also detected using agar plate culture technique.

Results: A total of 501 school children's samples were analyzed. The mean age at diagnosis was $10.0 \pm 1.6$ years. The prevalence of overall parasitic infections was $17.8 \%$ and identified as follows: Blastocystis sp. among 64 participants $(12.8 \%)$, Giardia duodenalis (1.4\%), Entamoeba coli (1.0\%), Opisthorchis viverrini $(0.8 \%)$, Enterobius vermicuralis $(0.6 \%)$, and Strongyloides stercolaris $(0.4 \%)$. A significantly increased risk of Blastocystis sp. infection was found in children studying in Schools B, C and A when compared with those studying at School D ( $p=0.001, \mathrm{OR}=4.36,95 \%$ $\mathrm{CI}=1.83-10.39, p=0.032, \mathrm{OR}=2.89,95 \% \mathrm{CI}=1.10-7.64$, and $p=0.033, \mathrm{OR}=2.2,95 \% \mathrm{CI}=1.06-4.54$, respectively). Drinking water was suspected to be the source of transmission. However, screening by PCR at the 18S rRNA gene for Blastocystis sp. could not detect the parasites from any sources of drinking water samples collected from the four schools. Conclusion: The most predominant intestinal protozoa infection in the studied school children was Blastocystis sp. The high prevalence of protozoa infection could reflect the hygienic conditions of the children. Thus, health education and the control of intestinal parasitic infections are necessary for these children.
\end{abstract}

Keywords : Blastocystis sp., cross-sectional study, parasitic infection, waterborne transmission

J Southeast Asian Med Res 2017; 1: 85-91.

http://www.jseamed.org

\section{Correspondence to:}

Suwannahitatorn P, Department of Parasitology, Phramongkutklao College of Medicine, Bangkok, Thailand E-mail: semisessile@gmail.com 


\section{Introduction}

Blastocystis sp., a single-cell protozoa, is one of the most common reported intestinal parasites in stool samples of humans. ${ }^{(1)}$ Four major host groups include humans, nonhuman primates, hoofed mammals and birds. ${ }^{(2-3)}$ So far, at least 17 subtypes (STs) have been identified among mammalian and avian species, of which human Blastocystis isolates are limited to STs 1-9. ${ }^{(5-8)}$ Much literature debates the pathogenic status of Blastocystis sp. ${ }^{(1,6,9,10)}$ This is mainly due to the fact that Blastocystis sp. can be found in both symptomatic and asymptomatic patients. ${ }^{(11,12)}$ However, recent studies have shown the relationship between Blastocystis $\mathrm{sp}$. infection and a variety of gastrointestinal symptoms especially irritable bowel syndrome. (6, 13, 14) $^{-1}$ Nonspecific gastrointestinal symptoms, such as diarrhea, abdominal cramping, nausea, vomiting, constipation and weight loss are the main features among infected patients. ${ }^{(1,6,9,10)}$ Blastocystis sp. has many potential modes of infection including fecal-oral route and waterborne transmission. ${ }^{(15-17)}$ Our previous studies revealed evidence of waterborne transmission of the same subtypes of Blastocystis sp. detected in fecal samples of school children and drinking water provided in the school. ${ }^{(18)}$ In addition, recent studies have shown zoonotic transmission caused by this organism because animal subtypes have been detected in human feces. ${ }^{(19-21)}$ Blastocystis $\mathrm{sp}$. is widely distributed throughout many regions, especially in developing countries. The prevalence of Blastocystis sp. infection varies from country to country and within communities of the same country. The prevalence of Blastocystis sp. infection in developing countries is higher than in developed countries. ${ }^{(1)}$ In Thailand, the study of Blastocystis sp. infection has shown the prevalence varied from $10 \%$ to $40 \%$ in different study populations. ${ }^{(18,22-24)}$ In our 2005 study, Blastocystis sp. infection was the most predominant species found among school children in a rural community $(18.7 \%$ of 675 stool samples). ${ }^{(18)}$ Because the highly prevalent nature of Blastocystis infection can be preventable, it may be used as a proxy indicator of the quality of environmental sanitation as well as the quality of drinking water provided in a community setting. ${ }^{(25)}$ Treatment of Blastocystis sp. infection should be considered among patients with persistent diarrhea and when no other pathogens except for Blastocystis sp. have been identified in fecal specimens. ${ }^{(26)}$ Metronidazole is considered as the first-line therapy for Blastocystis sp. infection. ${ }^{(27-29)}$

We conducted a cross-sectional study to determine the prevalence and associated risk factors of Blastocystis sp. among school children, studying at four primary schools in a rural community, central Thailand.

\section{Materials and Methods \\ Study population}

In November 2015, 4 of 12 local schools at a rural community of Sanam Chai Khet District, Chachoengsao Province were randomly selected by cluster sampling method. Primary school children from selected schools were enrolled in the study. The study was approved by the Institutional Review Board of the Royal Thai Army Medical Department. The study population comprised 700 children, aged from 6 to 12 years, studying in grades 1 to 6 of four primary schools. Informed consent was obtained from their parents and guardians before enrollment.

\section{Stool collection and examination}

Fresh feces samples, taken from school children, were examined immediately using the wet preparation method. Concentration methods were also performed using phosphate buffered saline-ethyl acetate and Kato-Katz techniques. Short-term cultivation for Blastocystis sp was performed using Jone's medium supplemented with $10 \%$ horse serum, incubated at $37^{\circ} \mathrm{C}$ and microscopically examined after 48 to 72 hrs. Strongyloides was also detected using agar plate culture technique.

\section{Water collection and extraction of DNA}

To determine the possible source of Blastocystis, samples of the water supply within four schools areas were collected and examined for Blastocystis using Polymerase Chain Reaction (PCR). Approximately $3,000 \mathrm{~mL}$ of water was collected from sources of drinking water in the four schools. A total of 14 water samples were collected, that is, sixsamples from school A (Na Esan), five from school B (Na Yao), two from school D (Poo Gnam), and one from school C (Tung Saw Hongsa). Water samples were enumerated by vacuum filtering through 0.22 um pore size and DNA of any organisms present in water was extracted from the trapped filter. DNA extraction was performed using a commercial kit (DNeasy Blood \& Tissue Kit, Qiagen, QIAamp Co Ltd) following the manufacturer instructions. Extracted DNA was kept at $-20^{\circ} \mathrm{C}$ until used for PCR amplification. 


\section{PCR amplification}

The 1,790 amplicon of the $18 \mathrm{~S}$ small subunit rRNA (SSU-rRNA) gene was amplified using a forward primer SR1F (5'GCT TAT CTG GTT GAT CCT GCC AGT AGT3') and a reverse primer SRIR (5'TGA TCC TTC CGC AGG TTC ACC TA3'). ${ }^{(30)}$ The PCR reaction in a 50 $\mu \mathrm{L}$ reaction comprised $2 \mu \mathrm{L}$ of extracted DNA, 50 pmol of each primer, $10 \mathrm{mM}$ of dNTP, $10 x \mathrm{MgCl}_{2}$ free PCR buffer, $1 \mathrm{mM}$ of $\mathrm{MgCl}_{2}$ and 1 unit of Taq DNA polymerase (GoTaq, Promega, USA). PCR reaction was amplified using the Perkin-Elmer Model 480 Thermal cycle. PCR condition consisted of the initial step at $94^{\circ} \mathrm{C}$ for $5 \mathrm{~min}$ and 30 cycles of denaturing at $94^{\circ} \mathrm{C}$ for $1 \mathrm{~min}$, annealing at $63^{\circ} \mathrm{C}$ for $1 \mathrm{~min}$, extending at $72^{\circ} \mathrm{C}$ for $1 \mathrm{~min} 30 \mathrm{sec}$ and an additional step to complete elongation at $72^{\circ} \mathrm{C}$ for $10 \mathrm{~min}$. PCR products were electrophoresed in $2.0 \%$ agarose gel and Tris-borate buffer. Gels were stained with ethidium bromide and the approximate sizes of the band profiles were estimated from the photographs.

\section{Questionnaire}

To identify associated risk factors and outcomes of Blastocystis sp. infection, a standardized questionnaire was designed to obtain information including demographic data, sanitary behavior, food consumption behavior, animal contact, source of drinking water, process for water treatment and history of gastrointestinal symptoms.

\section{Statistical analysis}

The $\chi^{2}$ test with $95 \%$ confidence interval (CI) was used to test associations between risk behaviors and Blastocystis sp. infection. Univariate analysis was performed using STATA/MP for Windows, version 12 (StataCorp LP, TX). Odds ratio (OR) with $95 \% \mathrm{CI}$ and $p$-value were calculated to compare outcomes in the study population. Logistic regression was performed for multivariate analysis to assess the independent association of risk behaviors and blastocystosis.

\section{Results}

In all, 501 participants were enrolled of which $497(99.2 \%)$ returned complete questionnaires. The characteristic of primary school children and prevalence of Blastocystis sp. infection in each group are shown in Table 1. Totally, 270 (54.3\%) females and $227(45.7 \%)$ males had the mean age of $10.0 \pm 1.6$ years. Enrolled participants from each primary school were as follows: school A (201, 40.4\%), school B
$(55,11.1 \%)$, school C $(52,10.5 \%)$, and school D (189, $38.0 \%)$. In these groups $88(20.1 \%)$ school children had intestinal parasitic infections. Some schools in this community joined the intestinal parasitic control program supported by the Ministry of Public Health and annually provided mass therapy for intestinal parasitic infections to school children; therefore, $293(60.8 \%)$ received antihelminthic drugs before this study. Due to different qualities of water supply in the community, $426(85.8 \%)$ children consumed rainwater or underground water and only $206(41.5 \%)$ consumed treated drinking water.

Table 1. Characteristics of enrolled students and prevalence of Blastocystis sp. infection $(\mathrm{n}=497)$

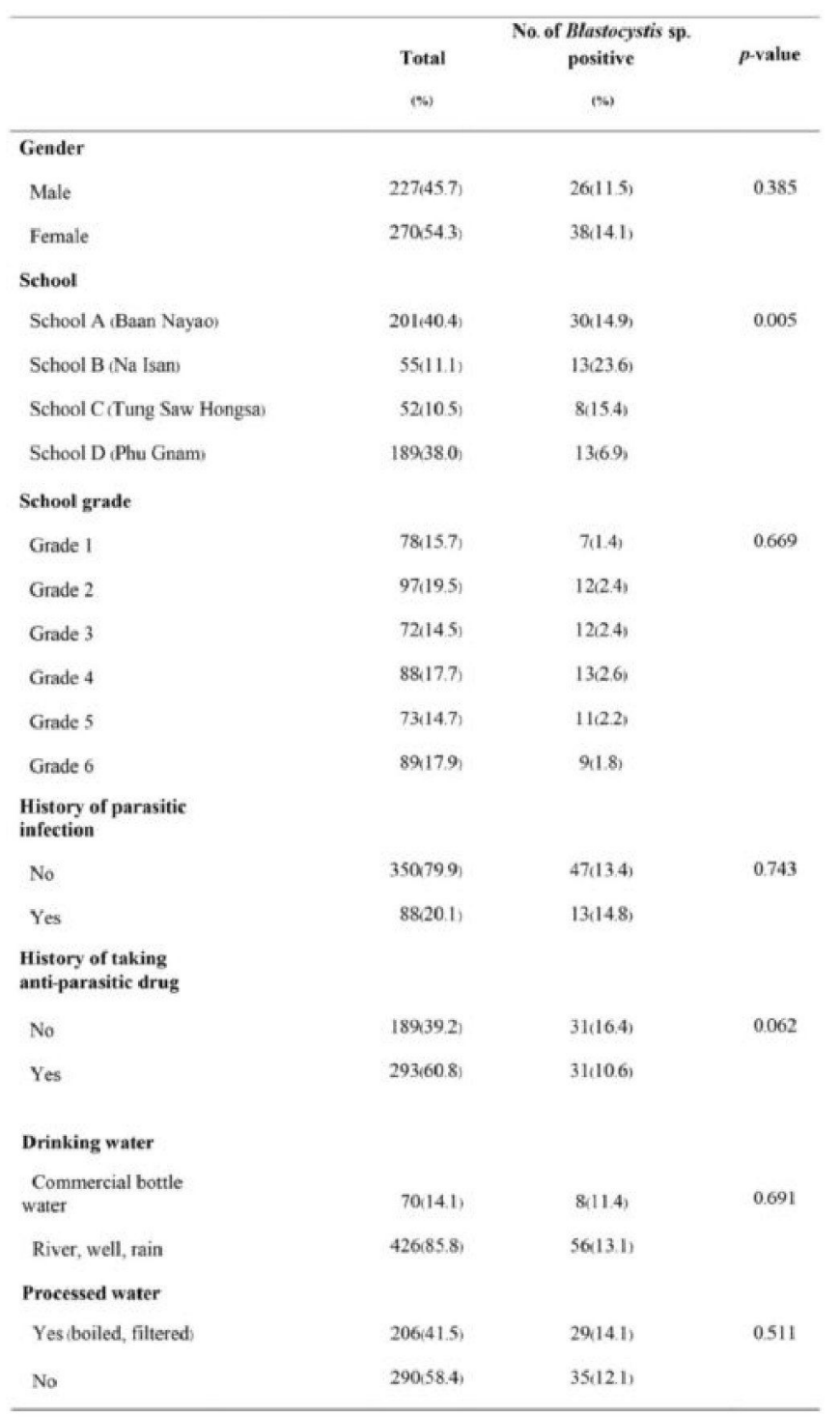

The prevalence of intestinal parasitic infections was $17.8 \%$ as shown in Table 2. Of 501 stool specimens, Blastocystis sp. was predominantly detected $(12.8 \%)$. 
Other intestinal parasitic infections included Giardiasis duodenalis $(7,1.4 \%)$, Entamoeba coli $(5,1.0 \%)$, Opisthorchis viverrini $(4,0.8 \%)$, Enterobius vermicularis $(3,0.6 \%)$ and Strogyloides stercolaris $(2,0.4 \%)$. Children who were infected with pathogenic intestinal parasites were treated using appropriate anti-parasitic drugs.

Table 2. Prevalence of parasitic infection $(n=501)$

\begin{tabular}{lcc}
\hline Parasite & Positive finding in feces & Prevalence \\
& n & $\%$ \\
\hline Blastocystis sp. & 64 & 12.8 \\
Giardia duodenalis & 7 & 1.4 \\
Entamoeba coli & 5 & 1.0 \\
Opisthorchis viverrini & 4 & 0.8 \\
Enterobius vermicularis & 3 & 0.6 \\
Strongyloides stercoralis & 2 & 0.4 \\
Others & 5 & 1 \\
\hline
\end{tabular}

Table 3. shows univariate and multivariate analysis of associated factors of Blastocystis sp. infection among the study population. Univariate analysis showed that studying in school A, B and C was significantly associated with the prevalence of Blastocystis sp. infection when compared with those studying in school D. After adjusting for the studied schools, the areas of raising livestock, source of drinking water and water treatment process before consuming, multivariate analysis showed that children who studied in schools B, C, and A had 4.36, 2.89, and 2.20 times at higher risk of acquiring Blastocystis sp. infection when compared with those studying in school $\mathrm{D}$ ( $p=0.001$, $\mathrm{OR}=4.36,95 \% \mathrm{CI}=1.83-10.39, p=0.032, \mathrm{OR}=2.89,95 \%$ $\mathrm{CI}=1.10-7.64$, and $p=0.033, \mathrm{OR}=2.2,95 \% \mathrm{CI}=1.06-4.54$, respectively).

To detect the DNA of Blastocystis sp. in drinking water, 14 water samples were collected from the four schools. Using 18S-rRNA-PCR, none of these water samples was positive for Blastocystis $\mathrm{sp}$.
Table 3. Univariate and multivariate analysis of associated risk factors of Blastocystis sp. infection

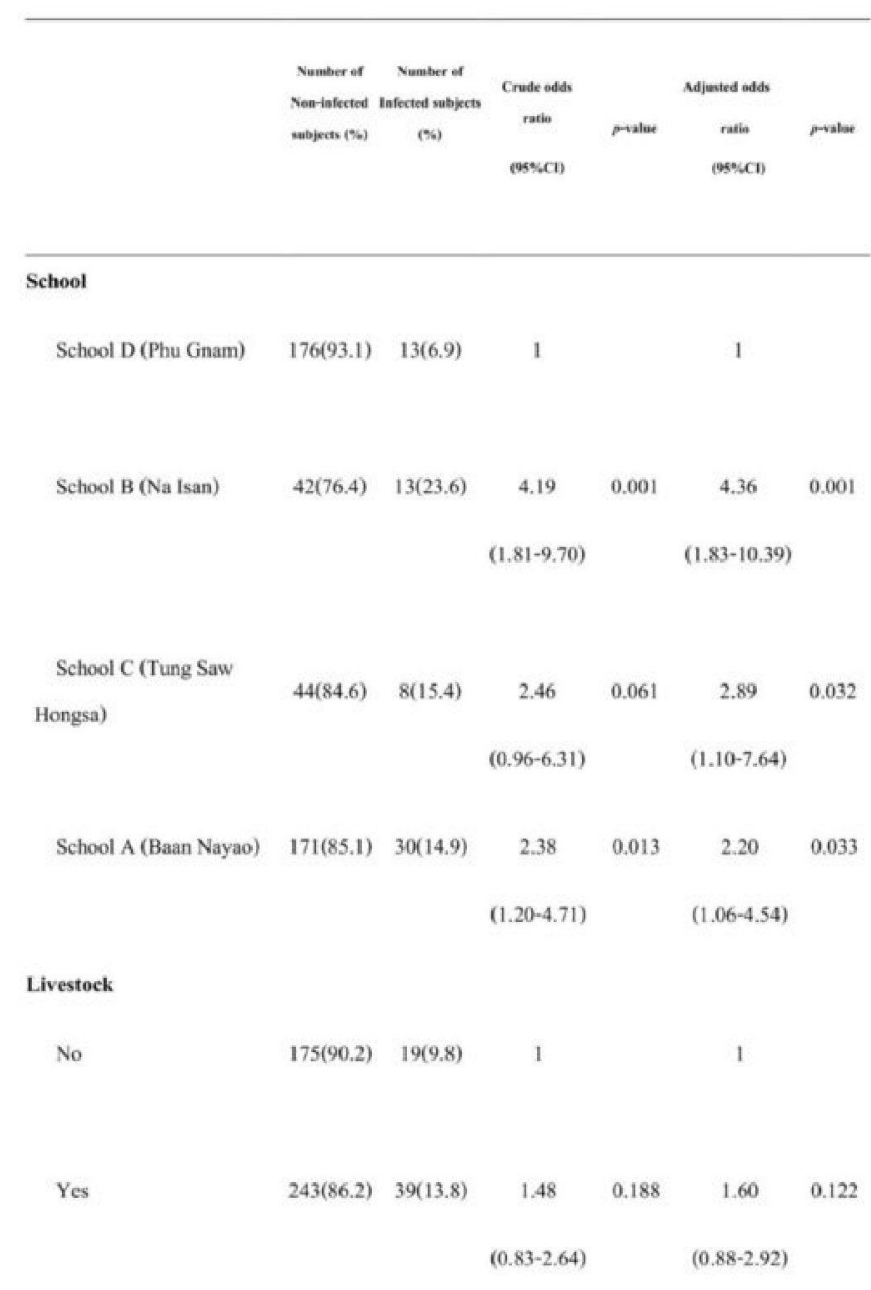

Drinking water

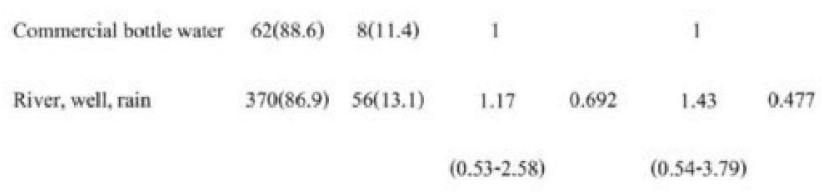

Processed water

$\begin{array}{llll}\text { Yes (boiled, filtered) } \quad 177(85.9) & 29(14.1) & 1 & 1\end{array}$

No

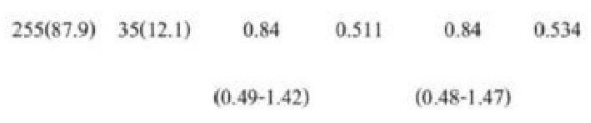

\section{Discussion}

In this study, Blastocystis sp. was the most predominant protozoa found in stool examinations of enrolled school children from four schools located in a rural community, central Thailand. In 2005, our studies among school children 
also showed similar results of the highest prevalence of Blastocystis sp. infection. Additionally, using 18S-rRNA-PCR showed that drinking water provided in the school could be the source of transmission because the same subtype was detected in both the study population and in drinking water. ${ }^{(18)}$ Thus, in this study, drinking water provided either at school or at home was suspected to be the source of transmission to these school children.

Using multivariate analysis, the independent risk factor associated with Blastocystis sp. infection was the school where children were studying. After interviewing the school director, one of different environmental factors identified among these schools was the source of drinking water. The school that revealed the lowest prevalence of Blastocystis sp. infection provided commercial bottled water as drinking water for their school children, while the other three schools provided untreated water. Other epidemiological studies showed that Blastocystis sp. infection was significantly associated with waterborne transmission. ${ }^{(31,32)}$ In this study, quality of drinking water did not significantly show an association with the infection. We were able to collect 14 samples of drinking water from the four schools. However, using 18S-rRNA-PCR, none of these water samples was positive for Blastocystis sp. Other sources of drinking water provided for children was at home which could be an important source of infection; however, we were unable to collect any water samples at home in this study. Therefore, the source of Blastocystis sp. transmission to school children needs further investigation. Among children, one study showed a strong association between Blastocystis sp, infection and poor nutritional status. ${ }^{(33)}$ Blastocystis sp. infection could be prevented by supplying quality treated water to the community and educating the community about treatment water process by boiling or filtering before consumption. Prevention and control of waterborne infection should follow, "Guidelines for Drinking-water Quality" Geneva 2008. The WHO, emphasizes this protozoon as one of the waterborne organisms and needs to be controlled by improving overall water quality. Thus, further improvement of drinking water is urgently needed within the community as well as in every school located in the area.

The prevalence of Blastocystis sp. varied in developed countries, ranged from 1.5 to $10 \%$, while in developing countries was between 30 to $50 \%$.
Additionally, the prevalences within the same country differ depending on study populations and study communities. In this study population, intestinal protozoa, for example, Blastocystis sp., Giardia duodenalis and Entamoeba coli, were predominant in the community. This finding was similar to the study performed by Ratanapo et al. in $2005 .{ }^{(24)}$ The prevalence of blastocystis infection in this study and that of Ratanpo et al. were $12.8 \%$ and $8.1 \%$, respectively, while other intestinal helminthic infections detected in stool specimens ranged from 0.1 to $1 \%$ in both studies. Due to a high sensitivity of short-term in vitro culture techniques to detect Blastocystis sp., the results of our study contrasted other studies conducted in different rural communities in Thailand where the prevalence of intestinal helminthic infections was higher than that of protozoan infection. ${ }^{(34)}$ Interventions such as health promotion and biannual mass chemotherapy of intestinal helminthic infections, which has been conducted by the Department of Disease Control (DDC, Thailand), Phramongkutklao College of Medicine and other organizations, have been successful. Using albendazole biannually, this public health policy may affect the prevalence of helminthic infection by decreasing the number of detected intestinal parasites, but has less effect on protozoan infection, i.e., Blastocystis sp. ${ }^{(35)}$

The prevalence of enterobiasis might have been underestimated because the standard diagnostic technique, "scotch-tape technique", was not applied in this study. Commonly reported parasitic infections among primaryschool-aged children, such as Ascaris lumbricoides, were not found.

Zoonotic transmission of Blastocystis sp. is a new and highly concerned issue because one recent study found that the Blastocystis sp. isolated from humans and animals living in the same accommodation had identical subtypes. ${ }^{(36)}$ However, the relation between livestock contact and Blastocystis sp. infection was not significantly associated in this study.

Using a cross-sectional method to study the prevalence of intestinal parasitic infections contributed to limitations involving temporal sequence. Preventable problems, i.e., improper management of data collection as well as unmatched stool specimens with answered questionnaires occurred in this study. This pitfall should be improved to prevent the loss of data. 


\section{Conclusion}

In conclusion, using in vitro culture technique, we describe the predominant Blastocystis sp. infection among schoolchildren of the four schools located in a rural community, central Thailand. Developing control programs to reduce the morbidity of intestinal protozoa infections especially, waterborne transmission diseases such as Blastocystis sp. infection among school children is required.

\section{References}

1. Stenzel DJ, Boreham PF. Blastocystis hominis revisited. Clin Microbiol Rev 1996; 9: 563-84.

2. Stensvold CR, Alfellani MA, Norskov-Lauritsen S, Prip $\mathrm{K}$, Victory EL, Maddox C, et al. Subtype distribution of Blastocystis isolates from synanthropic and zoo animals and identification of a new subtype. Int J Parasitol 2009; 39: 473-9.

3. Parkar U, Traub RJ, Vitali S, Elliot A, Levecke B, Robertson I, et al. Characterization of Blastocystis isolates from zoo animals and their animal-keepers. Vet Parasitol 2010; 169: 8-17.

4. Stensvold CR, Suresh GK, Tan KS, Thompson RC, Traub RJ, Viscogliosi E, et al. Terminology for Blastocystis subtypes-a consensus. Trends Parasitol 2007; 23: 93-6.

5. Thathaisong U, Worapong J, Mungthin M, Tan-Ariya P, Viputtigul K, Sudatis A, et al. Blastocystis isolates from a pig and a horse are closely related to Blastocystis hominis. J Clin Microbiol. 2003; 41: 967-75.

6. Tan KS. New insights on classification, identification, and clinical relevance of Blastocystis spp. Clin Microbiol Rev 2008; 21: 639-65.

7. Yersal O, Malatyali E, Ertabaklar H, Oktay E, Barutca S, Ertug S. Blastocystis subtypes in cancer patients: Analysis of possible risk factors and clinical characteristics. Parasitol Int 2016; 65: 792-6.

8. Parkar U, Traub RJ, Kumar S, Mungthin M, Vitali S, Leelayoova S, et al. Direct characterization of Blastocystis from feces by PCR and evidence of zoonotic potential. Parasitology 2007; 134: 359-67.

9. Boorom K, Smith H, Nimri L, Viscogliosi E, Spanakos G, Parkar U, et al. Oh my aching gut: irritable bowel syndrome, Blastocystis, and asymptomatic infection. Parasit Vectors 2008; 1: 40.
10. Tan K, Mirza H, Teo J, Wu B, Macary P. Current views on the clinical relevance of Blastocystis spp. Curr Infect Dis Rep 2010; 12: 28-35.

11. Dogruman-Al F, Dagci H, Yoshikawa H, Kurt O, Demirel M. A possible link between subtype 2 and asymptomatic infections of Blastocystis hominis. Parasitol Res 2008; 103: 685-9.

12. Eroglu F, Genc A, Elgun G, Koltas I. Identification of Blastocystis hominis isolates from asymptomatic and symptomatic patients by PCR. Parasitol Res 2009; 105: 1589-92.

13. Poirier P, Wawrzyniak I, Vivares C, Delbac F, El Alaoui $\mathrm{H}$. New insights into Blastocystis spp.: a potential link with irritable bowel syndrome. PLoS Pathog 2012; 8: e1002545.

14. Scanlan PD. Blastocystis: past pitfalls and future perspectives. Trends Parasitol 2012; 28: 327-34.

15. Leelayoova S, Rangsin R, Taamasri P, Naaglor T, Thathaisong U, Mungthin M. Evidence of waterborne transmission of Blastocystis hominis. Am J Trop Med Hyg 2004; 70: 658-62.

16. Lee LI, Chye TT, Karmacharya BM, Govind SK. Blastocystis sp.: waterborne zoonotic organism, a possibility? Parasit Vectors 2012; 5: 130.

17. Boondit J, Pipatsatitpong D, Mungthin M, Taamasri P, Tan-ariya $\mathrm{P}$, Naaglor $\mathrm{T}$, et al. Incidence and risk factors of blastocystis infection in orphans at the Babies' Home, Nonthaburi Province, Thailand. J Med Assoc Thai 2014; 97 Suppl 2: S52-9.

18. Leelayoova S, Siripattanapipong S, Thathaisong U, Naaglor T, Taamasri P, Piyaraj P, et al. Drinking water: a possible source of Blastocystis spp. subtype 1 infection in schoolchildren of a rural community in central Thailand. Am J Trop Med Hyg 2008; 79: 401-6.

19. Yoshikawa H, Wu Z, Pandey K, Pandey BD, Sherchand $\mathrm{JB}$, Yanagi T, et al. Molecular characterization of Blastocystis isolates from children and rhesus monkeys in Kathmandu, Nepal. Vet Parasitol. 2009; 160: 295-300.

20. Wang W, Owen H, Traub RJ, Cuttell L, Inpankaew T, Bielefeldt-Ohmann H. Molecular epidemiology of Blastocystis in pigs and their in-contact humans in Southeast Queensland, Australia, and Cambodia. Vet Parasitol 2014; 203: 264-9. 
21. Belleza ML, Cadacio JL, Borja MP, Solon JA, Padilla MA, Tongol-Rivera PN, et al. Epidemiologic study of Blastocystis infection in an urban community in the Philippines. J Environ Public Health 2015; 2015: 894297.

22. Warunee N, Choomanee L, Sataporn P, Rapeeporn Y, Nuttapong W, Sompong S, et al. Intestinal parasitic infections among school children in Thailand. Trop Biomed 2007; 24: 83-8.

23. Yaicharoen R, Ngrenngarmlert W, Wongjindanon N, Sripochang S, Kiatfuengfoo R. Infection of Blastocystis hominis in primary schoolchildren from Nakhon Pathom province, Thailand. Trop Biomed 2006; 23: $117-22$.

24. Ratanapo S, Mungthin M, Soontrapa S, Faithed C, Siripattanapipong S, Rangsin R, et el. Multiple modes of transmission of giardiasis in primary schoolchildren of a rural community, Thailand. Am J Trop Med Hyg 2008; 78: 611-5

25. Pipatsatitpong D, Leelayoova S, Mungthin M, Aunpad $\mathrm{R}$, Naaglor T, Rangsin R. Prevalence and risk factors for Blastocystis infection among children and caregivers in a child care center, Bangkok, Thailand. Am J Trop Med Hyg 2015; 93: 310-5.

26. Coyle C, Varughese J, Weiss L, Tanowitz H. Blastocystis: to treat or not to treat. Clin Infect Dis 2012; 54: 105-10.

27. Nigro L, Larocca L, Massarelli L, Patamia I, Minniti S, Palermo F, et al. A placebo-controlled treatment trial of Blastocystis hominis infection with metronidazole. J Travel Med 2003; 10: 128-30.

28. Moghaddam D, Ghadirian E, Azami M. Blastocystis hominis and the evaluation of efficacy of metronidazole and trimethoprim/sulfamethoxazole. Parasitol Res 2005; $96: 273-5$.
29. Stensvold C, Smith H, Nagel R, Olsen K, Traub R. Eradication of Blastocystis carriage with antimicrobials: reality or delusion? J Clin Gastroenterol 2010; 44: 85-90.

30. Yoshikawa H, Abe N, Iwasawa M, Kitano S, Nagano I, Wu Z, et al. Genomic analysis of Blastocystis hominis strains isolated from two long-term health care facilities. J Clin Microbiol 2000; 38: 1324-30.

31. Mungthin M, Suwannasaeng R, Naaglor T, Areekul W, Leelayoova S. Asymptomatic intestinal microsporidiosis in Thai orphans and child-care workers. Trans R Soc Trop Med Hyg 2001; 95: 304-6.

32. Taamasri $\mathrm{P}$, Mungthin $\mathrm{M}$, Rangsin R, Tongupprakarn $\mathrm{B}$, Areekul W, Leelayoova S. Transmission of intestinal blastocystosis related to the quality of drinking water. Southeast Asian J Trop Med Public Health 2000; 31:112-17.

33. Manganelli L, Berrilli F, Di Cave D, Ercoli L, Capelli $\mathrm{G}$, Otranto D, et al. Intestinal parasite infections in immigrant children in the city of Rome, related risk factors and possible impact on nutritional status. Parasit Vectors 2012; 5: 265.

34. Waikagul J, Krudsood S, Radomyos P, Radomyos B, Chalemrut $\mathrm{K}$, Jonsuksuntigul $\mathrm{P}$, et al. A cross-sectional study of intestinal parasitic infections among schoolchildren in Nan Province, Northern Thailand. Southeast Asian J Trop Med Public Health 2002; 33: 218-23.

35. Speich B, Marti H, Ame SM, Ali SM, Bogoch II, Utzinger $\mathrm{J}$, et al. Prevalence of intestinal protozoa infection among school-aged children on Pemba Island, Tanzania, and effect of single-dose albendazole, nitazoxanide and albendazole-nitazoxanide. Parasit Vectors. 2013; 6: 3.

36. Parkar U, Traub RJ, Kumar S, Mungthin M, Vitali S, Leelayoova S, et al. Direct characterization of Blastocystis from faeces by PCR and evidence of zoonotic potential. Parasitology 2007; 134: 359-67. 